\title{
Rendimento do Trabalho das Esposas e Tendências da Desigualdade de Renda no Brasil (1992-2014)
}

\author{
Carlos Antonio Costa Ribeiro ${ }^{1}$ \\ Weverthon Machado ${ }^{1}$ \\ Universidade do Estado do Rio de Janeiro (UERJ), Rio de Janeiro, RJ, Brasil. E-mail: \\ carloscr@iesp.uerj.br
}

\section{INTRODUÇÃO}

$\mathrm{D}$ urante as duas últimas décadas o Brasil experimentou um crescimento constante da participação feminina na força de trabalho, um aumento expressivo da contribuição financeira das esposas em casamentos heterossexuais e uma queda significativa da desigualdade de renda. Neste artigo argumentamos que as três tendências estão interligadas, tendo em vista que o crescimento da participação feminina se deu principalmente pela entrada das mulheres casadas no mercado de trabalho, o que por sua vez contribuiu para a diminuição da desigualdade de renda. Entre 1992 e 2014 o percentual de mulheres solteiras com rendimentos do trabalho maior do que zero praticamente não mudou, ficando em torno de $65 \%$. Em contraste, as mulheres casadas aumentaram sua participação de 38\% em 1992 para 56\% em 2014. Os dados indicam que mudanças importantes estão ocorrendo nas finanças dos casais no Brasil, na medida em que as esposas estão contribuindo cada vez mais com rendimentos próprios. Nesse mesmo período a desigualdade de renda entre as famílias diminuiu cerca de $30 \%$. Nossas análises neste artigo sugerem que o impacto da participação feminina no mercado de trabalho nas tendências da desigualdade de renda no Brasil está diretamente relacionado às mudanças nos padrões de casamento que vêm ocorrendo ao longo das décadas.

Mudanças similares nas finanças dos casais, que também ocorreram em diversos outros países, levaram algumas sociólogas norte-america-

DADOS - Revista de Ciências Sociais, Rio de Janeiro, vol. 61, no1, 2018, pp. 103 a 135.

http://dx.doi.org/10.1590/001152582018148 
nas (Oppenheimer, 1988; Sweeney, 2002) a criticar o modelo econômico do casamento sugerido por Becker $(1974,1977)$. Enquanto Becker (1974) previa correlação negativa entre a renda de maridos e esposas porque a dedicação dos maridos ao mercado de trabalho seria mais eficiente para os casais se as esposas se dedicassem ao trabalho doméstico, Oppenheimer (1988) e Sweeney (2002) sugerem que um modelo mais colaborativo de casamento estaria se expandindo nos Estados Unidos, o que se expressaria em uma correlação positiva e crescente entre os rendimentos dos cônjuges. Nossas análises indicam, como as de Sweeney (2002), uma correlação positiva e crescente entre os rendimentos de maridos e esposas no Brasil, bem como uma diminuição da desigualdade entre as esposas e um aumento da proporção da renda domiciliar devido ao trabalho das esposas. Dentre as diversas consequências que essas mudanças trazem para as famílias e para o mercado de trabalho, destacamos neste artigo os efeitos para as tendências da desigualdade de renda no país. Em outras palavras, argumentamos que as características da distribuição de rendimentos das mulheres casadas estão se tornando cada vez mais relevantes para entendermos as tendências da desigualdade de renda no Brasil.

A literatura sobre distribuição de renda no Brasil mostrou que a desigualdade, tanto dos rendimentos do trabalho quanto da renda familiar, diminuiu significativamente a partir de meados da década de 1990 e mais intensamente ao longo da década de 2000. Estudos recentes sobre o tema vêm mostrando que os seguintes fatores contribuíram para a diminuição observada: aumento real do salário mínimo, aumento do acesso à educação, diminuição da taxa de dependência (número de pessoas ativas em relação a inativas nos domicílios), mudanças na estrutura ocupacional, políticas públicas (Bolsa Família, entre outras) e diminuição da desigualdade regional (Barros, Foguel e Ulyssea, 2007; Carvalhaes et al., 2014; Souza e Carvalhaes, 2014; Menezes-Filho e Rodrigues, 2009; Soares, 2002). O principal fator parece ter sido a expansão educacional (Menezes-Filho e Oliveira, 2014).

Apesar de todos esses aspectos serem extremamente importantes, pouca atenção tem sido dada à relação entre os rendimentos de homens e de mulheres nas tendências da desigualdade de renda. Barros e Mendonça (1989), analisando dados das regiões metropolitanas na Pesquisa Nacional por Amostra de Domicílio (PNAD) 1985, concluíram que a desigualdade de rendimentos das esposas era mais alta que a dos maridos, mas seu impacto na desigualdade entre famílias era 
Rendimento do Trabalho das Esposas e Tendências da Desigualdade de Renda...

anulado pela associação imperfeita entre os rendimentos dos cônjuges. Sedlacek e Santos (1991) investigaram a relação entre a renda do marido e a participação da mulher do mercado de trabalho em 1984 e encontraram maiores taxas de participação para esposas dos maridos nos dois extremos da distribuição de renda. Hoffmann e Leone (2004) e Scorzafave e Menezes-Filho (2005) analisaram a participação feminina no mercado de trabalho e seus efeitos na desigualdade de renda nos períodos de 1981 a 2002 e 1982 a 1997, respectivamente, mas não diferenciaram o rendimento das esposas do rendimento de todas as mulheres. Em contraste, argumentamos que, para entender os efeitos do trabalho remunerado das mulheres nas tendências da desigualdade nas décadas de 1990 e 2000, devemos levar em conta, particularmente, as mudanças na distribuição de rendimento das mulheres em união.

Sendo assim, nos propomos a analisar o impacto das tendências na distribuição dos rendimentos das mulheres em união conjugal na tendência de diminuição da desigualdade de renda familiar no período de 1992 a 2014. Para tanto usamos uma equação de decomposição que separa famílias chefiadas por casais de outros tipos de famílias (decomposição entre grupos populacionais) e, para os casais, distingue o impacto dos rendimentos das esposas do impacto de outras fontes de renda (decomposição por fontes de renda). Embora em 1985 o impacto dos rendimentos das esposas na desigualdade de renda tenha sido muito pequeno (Barros e Mendonça, 1989), nossas análises e decomposições revelam que nas décadas de 1990 e 2000 as mudanças nas características da distribuição de rendimento do trabalho das esposas contribuíram significativamente para a diminuição da desigualdade de renda. Usando a metodologia de decomposição da desigualdade de renda, simulamos o nível de desigualdade que existiria se os rendimentos do trabalho das esposas não tivessem se modificado desde o início da década de 1990.

Nas duas últimas décadas ocorreram mudanças importantes na distribuição de renda do país. Por um lado, estudos usando dados da PNAD do Instituto Brasileiro de Geografia e Estatística (IBGE) revelam que nas décadas de 1990 e 2000 houve diminuição da desigualdade de renda. Embora essa diminuição tenha sido muito propagandeada nos meios de comunicação e nos discursos políticos, sabemos atualmente que, quando a renda no topo da distribuição é mensurada usando dados do imposto de renda, a queda pode não ter sido realmente significativa (Medeiros, Souza e Castro, 2015). Tendo em vista que pesquisas 
domiciliares em qualquer país não medem bem o que ocorre no topo da distribuição (entre os 1\% mais ricos, por exemplo) e que há forte concentração de renda no topo, não é totalmente surpreendente que os dados do imposto de renda indiquem estabilidade na desigualdade entre 2006 e 2012. Nossa interpretação, no entanto, é que as pesquisas domiciliares continuam a ser fontes bastante confiáveis para mensurar o que ocorre pelo menos entre os $95 \%$ ou $99 \%$ mais pobres da distribuição. Por outro lado, sabemos que ocorreram não apenas mudanças significativas na participação feminina no mercado de trabalho como também uma enorme ampliação do percentual de mulheres completando níveis educacionais mais elevados. Por exemplo, hoje em dia há mais mulheres que homens com ensino médio e superior completos. Tais mudanças, como sugerimos neste artigo, se expressam no aumento da contribuição que as mulheres casadas dão para a renda domiciliar. A proporção do rendimento das esposas na renda familiar aumentou consideravelmente (de 17\% em 1992 para 27\% em 2014), a desigualdade dos rendimentos do trabalho das esposas diminuiu muito mais do que a dos rendimentos dos maridos e, além disso, a correlação entre as rendas dos cônjuges aumentou bastante - era 0,36 em 1992 e passou a ser 0,50 em 2014. Esses dados indicam que é importante considerar as características da distribuição dos rendimentos do trabalho das esposas para entender melhor as mudanças que ocorreram nas últimas décadas.

De fato, nossas análises revelam, por um lado, que o aumento da contribuição das esposas para a renda das famílias e a diminuição da desigualdade de renda entre as esposas estão fortemente associadas à tendência de queda da desigualdade entre as famílias. Por outro lado, mostramos que a correlação entre as rendas de maridos e esposas contribuiu para atenuar esse movimento de queda. Dessa forma, a diminuição da desigualdade de renda entre 1992 e 2014 parece estar relacionada, positiva e negativamente, não apenas à crescente contribuição das mulheres para a renda familiar, como também aos padrões de casamentos em termos das rendas dos cônjuges.

O artigo está dividido em oito partes, sendo a primeira esta introdução. Na segunda parte descrevemos o contexto relacionado à desigualdade de renda no Brasil nas décadas de 1990 e 2000 e o debate teórico sobre casamento e renda familiar. Na parte seguinte fazemos definições conceituais e descrevemos a metodologia utilizada. Na quarta indicamos as características dos dados e amostras. Na quinta parte 
Rendimento do Trabalho das Esposas e Tendências da Desigualdade de Renda...

descrevemos as mudanças observadas nos componentes da renda entre 1992 e 2014. Nas partes seis e sete desenvolvemos as análises contrafatuais e, na última, concluímos.

\section{CONTEXTO DE MUDANÇAS}

A evolução da desigualdade de renda no Brasil é um tema amplamente estudado. Desde pelo menos o Censo de 1960, e com dados ainda melhores das PNADs a partir de meados da década de 1970, a desigualdade de renda vem sendo monitorada e discutida em trabalhos acadêmicos de alta qualidade. Os estudos mostram os impactos de diversas políticas e mudanças na estrutura social que contribuíram para explicar tanto o aumento da desigualdade entre as décadas de 1960 e 1990 quanto sua tendência de diminuição a partir de meados da década de 1990 (Langoni, 2005; Ferreira et al., 2006) e a queda ainda mais acentuada a partir da década de 2000 (Barros, Foguel e Ulyssea, 2007).

Salta aos olhos, no entanto, o pequeno número de trabalhos investigando o papel dos rendimentos do trabalho das mulheres, em particular das mulheres casadas, nas tendências observadas. Uma exceção é o artigo de Hoffmann e Leone (2004) sobre as consequências da participação feminina no mercado de trabalho e as mudanças na desigualdade de renda entre 1981 e 2002. A pesquisa mostra que em 1981 o rendimento das mulheres equivalia a $55,7 \%$ do rendimento dos homens, ao passo que em 2002 já equivalia a $70,6 \%$. Ou seja, diminuiu a desigualdade de gênero e o rendimento do trabalho das mulheres passou a contribuir cada vez mais para a renda das famílias. Hoffmann e Leone (2004) afirmam que o efeito do aumento dos rendimentos das mulheres nas tendências de desigualdade depende das características da correlação com outras fontes de rendimentos. Se o crescimento da participação ocorresse apenas para mulheres com rendas mais altas haveria aumento da desigualdade, mas se ocorresse para mulheres com rendas médias ou baixas haveria diminuição da desigualdade. Os autores concluem que o aumento da participação feminina foi mais intenso no meio da distribuição de renda entre 1981 e 2002, o que contribuiu para que houvesse uma tendência de queda da desigualdade a partir de meados da década de 1990. Entre 1992 e 2014 o aumento da participação das mulheres em união se deu principalmente acima da distribuição de renda dos maridos e a correlação entre os rendimentos do trabalho dos cônjuges serviu como um freio, enfraquecendo a tendência de queda da desigualdade ${ }^{1}$. Além disso, mostramos que a queda da

DADOS - Revista de Ciências Sociais, Rio de Janeiro, vol. 61, no 1, 2018 
desigualdade entre as mulheres e o aumento da sua renda média também foram fatores importantes contribuindo para a diminuição da desigualdade entre famílias. Essas conclusões, que discutimos mais adiante, merecem ser investigadas em mais detalhe, em parte porque nossas análises revelam algo pouco explorado anteriormente: o aumento da participação feminina se deu sobretudo por causa do aumento da renda das mulheres em união.

A Figura 1 evidencia que o crescimento da participação feminina no mercado de trabalho no período que estamos analisando foi fruto sobretudo da incorporação das mulheres que viviam em uniões conjugais ${ }^{2}: 56 \%$ delas tinham renda proveniente do trabalho em 2014, contra $37,7 \%$ em 1992, considerando apenas as mulheres entre 25 e 55 anos. A proporção de mulheres em união vem diminuindo, mas elas ainda são a maioria nessa faixa etária $-66 \%$ em 2014 , seis pontos percentuais a menos que no início do período - por isso seu comportamento influencia fortemente a tendência geral. Entre as mulheres que não viviam em companhia de cônjuge ou companheiro, o percentual com renda do trabalho variou pouco, passando de $64,5 \%$ para $67,4 \%$. Não é surpresa que mulheres que não estão em união tenham níveis maiores de

Figura 1

Percentual de Mulheres (25 a 55 anos) com Renda do Trabalho Maior que Zero, por Situação Conjugal

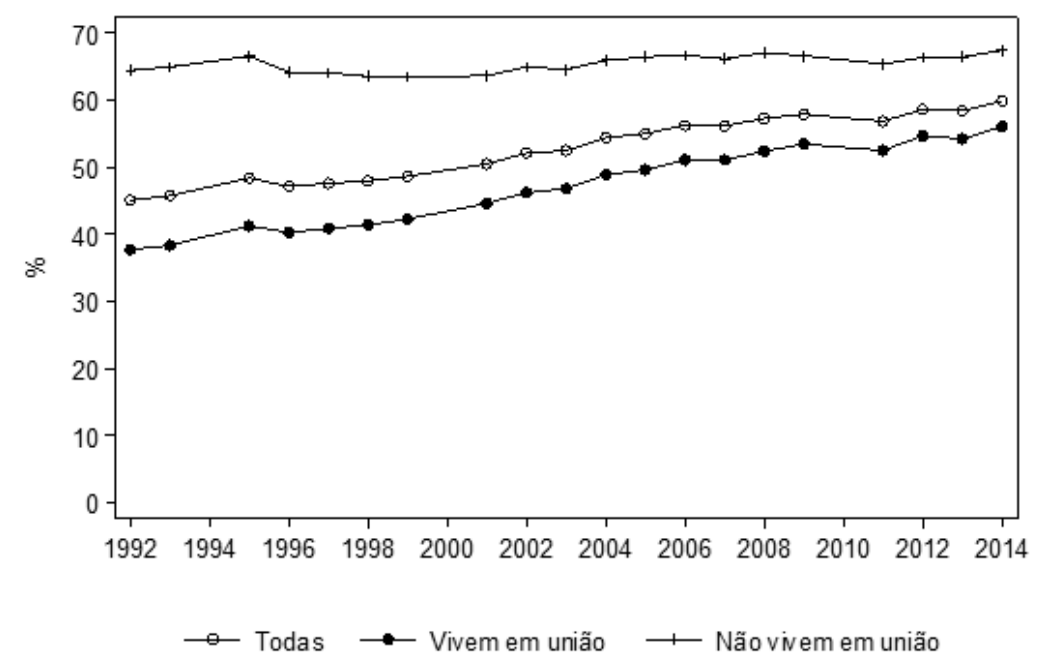

Fonte: Elaboração própria com dados das PNADs 1992-2014. 
Rendimento do Trabalho das Esposas e Tendências da Desigualdade de Renda...

participação no mercado de trabalho, visto que tendem a depender mais de rendimentos próprios. O que é realmente interessante é o fato de os casais estarem cada vez mais contando com os rendimentos do trabalho das esposas. Nesse sentido, os dados da Figura 1 revelam um fato sociológico relevante sobre mudanças no comportamento das mulheres em união e de seus companheiros.

Apesar da diversificação dos arranjos familiares nas últimas décadas com crescimento, por exemplo, de famílias monoparentais, unipessoais e casais do mesmo sexo (Wajnman, Turra e Agostinho, 2007; IBGE, 2010; Itaboraí, 2015) - os domicílios chefiados por casais heterossexuais com ou sem filhos continuam a ser maioria no Brasil ${ }^{3}$. No entanto, o perfil dos arranjos conjugais também vem se modificando muito. Entre as mudanças podemos destacar três que obviamente estão inter-relacionadas: o número de filhos por casais vem diminuindo (Ribeiro, 2014), a idade do primeiro casamento vem aumentando para as mulheres (idem), e a participação das mulheres em união no mercado de trabalho vem se ampliando (ver Figura 1). Tais tendências podem estar associadas tanto a mudanças culturais e sociais importantes que dizem respeito ao papel das mulheres nas famílias e no mercado de trabalho, quanto às necessidades econômicas das famílias que dependem crescentemente dos rendimentos das esposas. Aparentemente os casais estão passando do modelo definido por Becker (1974) como de especialização e troca dentro das famílias - em que os maridos contribuem com recursos financeiros e as esposas com cuidados domiciliares (filhos e trabalho doméstico) - para outro definido por Sweeney (2002), marcado por uma colaboração mais simétrica - em que maridos e esposas contribuem com renda e com trabalho doméstico. Embora mais pesquisas e detalhes sobre essa mudança sejam necessários, a Figura 1 sugere que o Brasil está caminhando nessa direção, assim como estão fazendo outros países.

A teoria formulada por Becker (1974) procura definir os casamentos do ponto de vista da eficiência econômica das famílias. De acordo com essa teoria, se os homens ganham em média mais do que as mulheres, há uma tendência para um equilíbrio em que maridos se especializam no mercado de trabalho e esposas no trabalho doméstico. Essa combinação seria mais eficiente do ponto de vista da produtividade familiar medida em termos financeiros e econômicos. Nesse sentido, Becker (1974:313) afirma: "A negative correlation between $\mathrm{w}_{\mathrm{m}}$ (males' earnings) and $\mathrm{w}_{\mathrm{f}}$ (females' earnings) maximizes total output because

DADOS - Revista de Ciências Sociais, Rio de Janeiro, vol. 61, nº 1, 2018 
the gains from the division of labor is maximized." Ao incluir em suas equações a relevância da produtividade no trabalho doméstico, Becker (1974) produziu um modelo muito instrutivo para explicar não apenas a eficiência econômica das famílias, mas também a desigualdade de gênero. Em um artigo posterior, Becker, Landes e Michael (1977) desenvolveram a teoria e mostraram que havia uma correlação positiva entre os rendimentos do trabalho das mulheres e as chances de divórcio. Usando dados transversais (cross-section) com informação retrospectiva sobre datas dos primeiros casamentos, dos divórcios e eventuais casamentos subsequentes, Becker e seus colaboradores (1977:1183) mostraram que aumentos nos rendimentos dos maridos diminuem as chances de divórcio, enquanto aumentos nos rendimentos das esposas aumentam as chances de divórcio.

As análises de Becker $(1974,1977)$ foram feitas com base em dados das décadas de 1960 e 1970. Dados mais recentes, das décadas de 1980 e 1990, parecem contradizer suas previsões na medida em que mostram claramente a configuração de um novo padrão de combinação entre rendimentos de maridos e esposas. Os dados analisados por Sweeney (2002), por exemplo, indicam que, para pessoas entrando nos primeiros casamentos na década de 1980, a renda das mulheres estava positivamente correlacionada às chances de casamento - ou seja, o potencial econômico das mulheres facilitava sua entrada em uniões, o oposto do que seria esperado em um modelo de especialização e troca. Esses resultados sugerem que a teoria de Becker (1974) não seria adequada para explicar os padrões de casamento a partir da década de 1980 nos Estados Unidos. Sendo assim, Sweeney (2002) sugere que as evidências favorecem a explicação sociológica avançada pela teoria da entrada no casamento de Oppenheimer (1988), que enfatiza a importância da posição econômica de ambos os cônjuges para as escolhas matrimoniais. Adaptando a "teoria da busca de trabalho" (que também foi utilizada parcialmente por Becker) para analisar o mercado de casamentos, Oppenheimer (1988) sugere que a idade de entrada no casamento aumenta tanto para homens quanto para mulheres porque para ambos está se tornando importante desenvolver qualificações voltadas para o mercado de trabalho. As análises usando dados contemporâneos parecem favorecer a perspectiva de Oppenheimer (1988) e Sweeney (2002) na medida em que a posição econômica de ambos os cônjuges se torna cada vez mais importante para explicar as tendências de casamento e divórcio. Ao analisar a entrada no primeiro casamento usando dados longitudinais, Sweeney (2002) mostrou que, nas coortes 
Rendimento do Trabalho das Esposas e Tendências da Desigualdade de Renda...

mais jovens, a renda e a educação formal das mulheres americanas se tornaram mais relevantes para as chances do primeiro casamento, que consequentemente está ocorrendo em idades um pouco mais altas para ambos os sexos.

Os dados brasileiros também parecem favorecer a teoria que enfatiza a correlação positiva entre rendimentos dos cônjuges e a Figura 1 é evidência nessa direção. Nossa principal questão é saber em que medida mudanças no papel das mulheres no mercado de trabalho e dentro das famílias estão relacionadas às tendências da desigualdade de renda. Tais mudanças são fruto de uma série de modificações institucionais e culturais que vêm ocorrendo ao longo das décadas. Entre as mudanças institucionais, duas merecem destaque: a ampliação do sistema educacional e o aumento de proteções no mercado de trabalho. A expansão do ensino elementar no Brasil se deu tardiamente se comparada à de outros países, tendo em vista que foi apenas na década de 1990 que esse nível educacional chegou próximo da universalização. Já o ensino superior se desenvolveu de outra forma: nos anos 1970 experimentou uma enorme expansão, dobrando o número de vagas, e voltou a crescer nos últimos 15 anos. Essa expansão, tanto do ensino elementar quanto do superior, certamente favoreceu as mulheres, que ao longo dos anos ultrapassaram os homens em termos de desempenho e progressão no sistema educacional. Assim, as mulheres passaram a entrar no mercado de trabalho mais qualificadas. Além disso, principalmente a partir da Constituição de 1988, um conjunto de políticas de proteção ao trabalho feminino, como licença maternidade e proteção do emprego de mulheres grávidas, foi se expandindo. Paralelamente, a economia do país vem ampliando o setor de serviços - notoriamente um setor que emprega muito as mulheres - em detrimento do rural e do industrial. Não há dúvidas de que essas mudanças no sistema educacional e no mercado de trabalho favorecem o trabalho feminino e tornam os rendimentos das mulheres mais proeminentes. Ao mesmo tempo, o papel das mulheres dentro das famílias vem se modificando muito na medida em que o trabalho fora do domicílio se torna uma exigência não apenas econômica, mas também cultural.

Mudanças no papel das mulheres nas famílias, no sistema educacional e no mercado de trabalho parecem ser consequência de processos seculares de ampliação de valores e atividades favorecendo a igualdade de gênero; ou seja, não são fruto simplesmente de políticas específicas dos últimos governos brasileiros entre as décadas de 1990 e 2000. Essas

DADOS - Revista de Ciências Sociais, Rio de Janeiro, vol. 61, nº 1, 2018 
transformações estão em parte relacionadas à luta dos movimentos feministas, embora seja muito difícil traçar ligações diretas entre este tipo de atividade política e as mudanças nos rendimentos das mulheres. Além disso, é preciso investigar melhor por que foram as mulheres em união que mais aumentaram sua participação no mercado de trabalho. Neste artigo nos limitamos a analisar o impacto dos rendimentos das mulheres em união nas tendências de desigualdade nas últimas duas décadas, mas é importante entender que essas mudanças são consequência tanto de mudanças de valores - por mais igualdade de gênero - como também de necessidades econômicas - complementaridade entre rendimentos de maridos e esposas. A interpretação sociológica não nega a racionalidade econômica dos mercados de casamento, mas enfatiza que essa racionalidade não pode ser pensada independentemente de valores e instituições mais amplas. Na medida em que esses valores e instituições se modificam, os padrões de casamento também se modificam. Consequentemente, as tendências de desigualdade dependem, em parte, de mudanças sociológicas ocorrendo dentro das famílias contemporâneas.

\section{DEFINIÇÕES CONCEITUAIS E METODOLOGIA: RENDA DO TRABALHO DAS ESPOSAS E DESIGUALDADE DE RENDA FAMILIAR}

Nesta seção apresentamos algumas definições conceituais e os contrafatuais que usamos para mensurar o impacto das mudanças nos rendimentos das mulheres casadas na tendência de desigualdade de renda familiar. Além disso, descrevemos as decomposições aqui utilizadas.

\section{Contrafatuais para Análise do Impacto dos Rendimentos do Trabalho das Esposas}

Para analisar o impacto de diferentes fontes de rendimentos dos membros das famílias na desigualdade de renda, pesquisadores frequentemente comparam as distribuições observadas com distribuições hipotéticas, ou seja, distribuições que existiriam caso alguma fonte de renda tivesse se comportado de uma maneira diferente. Tais distribuições hipotéticas são conhecidas como contrafatuais. Para estimar o impacto dos rendimentos do trabalho das esposas na desigualdade de renda das famílias utilizamos, baseados em Cancian e Reed (1999), quatro exercícios contrafatuais. Quando a distribuição de renda observada é mais igualitária do que a distribuição simulada sob determinado contrafatual, pode-se considerar que o rendimento do trabalho das 
Rendimento do Trabalho das Esposas e Tendências da Desigualdade de Renda...

esposas teve um papel equalizador. Para analisar o impacto do rendimento das esposas em um ano específico, comparamos a distribuição de renda que de fato ocorreram com a distribuição que teríamos prevalecido se:

Contrafatual 1: todas as esposas não tivessem rendimentos (renda zero).

Contrafatual 2: houvesse uma diminuição marginal no rendimento das esposas.

Também analisamos o impacto das mudanças na distribuição de rendimentos do trabalho das esposas ao longo do tempo. Para tanto comparamos a distribuição observada com a distribuição que teria ocorrido caso:

Contrafatual 3: a média e a dispersão do rendimento das esposas não tivessem mudado.

Contrafatual 4: a média, a dispersão e a correlação entre o rendimento das esposas e as outras fontes de renda não tivessem mudado.

Note-se que o quarto contrafatual inclui as mudanças nas correlações entre os rendimentos das esposas e as outras fontes de renda familiar. É importante estimar o impacto das tendências no rendimento das esposas com e sem as mudanças nas correlações porque essas mudanças não podem ser atribuídas a uma única fonte de renda (Cancian e Reed, 1999).

Em suma, apresentamos resultados seguindo duas estratégias analíticas. A primeira (contrafatuais 1 e 2) avalia o impacto do rendimento das esposas em determinados momentos no tempo. Apesar de esta primeira estratégia permitir descrever tendências hipotéticas ao longo do tempo se aplicada a uma série de anos consecutivos, ela não permite avaliar os efeitos das mudanças de facto nos rendimento das esposas nas tendências observadas. A segunda estratégia analítica (contrafatuais 3 e 4) é adequada para medir o impacto das mudanças nos rendimentos das esposas nas mudanças na desigualdade de renda familiar, mantendo outros aspectos constantes. É possível, portanto, mensurar qual a contribuição dada pelas mudanças nos rendimentos das esposas para a tendência bastante conhecida de diminuição da desigualdade de renda familiar no Brasil entre 1992 e 2014 (Ferreira et al., 2006).

DADOS - Revista de Ciências Sociais, Rio de Janeiro, vol. 61, nº 1, 2018 


\section{Métodos}

Para mensurar a desigualdade de renda e testar os contrafatuais apresentados acima usamos uma metodologia desenvolvida por Cancian e Reed (1999). Essa metodologia usa uma medida bastante conhecida da desigualdade de renda: o coeficiente de variação $(\mathrm{CV})$ - que é definido pelo desvio padrão da distribuição da renda dividido pela média aritmética desta mesma distribuição - elevado ao quadrado. Em um importante artigo, Shorrocks (1983) propôs uma série de decomposições para diversas medidas de desigualdade. Essas ferramentas já foram amplamente usadas na literatura sobre desigualdade de renda no Brasil (por exemplo, em alguns capítulos de Barros et al., 2007). Cancian e Reed (1999) propuseram modificações com o objetivo de elaborar distribuições contrafatuais que pudessem ser usadas como referência para determinarmos a contribuição de cada componente da renda para a desigualdade observada. Nesse sentido, mostram que a distribuição da renda dos casais depende da distribuição de cada uma das fontes de renda familiar, da magnitude relativa de cada fonte, e das correlações entre as fontes de renda. A equação de decomposição que propõem para o coeficiente de variação ilustra essas relações:

$$
\begin{aligned}
& \text { (1) } C V_{f}^{2}=S_{h}^{2} C V_{h}^{2}+S_{m}^{2} C V_{m}^{2}+S_{r}^{2} C V_{r}^{2}+2 \rho_{h m} S_{h} S_{m} C V_{h} C V_{m} \\
& +2_{\rho h r} S_{h} S_{r} C V_{h} C V_{r+} 2 \rho_{m r} S_{m} S_{r} C V_{m} C V_{r} \\
& \text { onde: } S_{\kappa}=\frac{\kappa_{\mu}}{\mu_{h}+\mu_{m}+\mu_{r}}
\end{aligned}
$$

$C V_{\mathrm{K}}$ é o coeficiente de variação para o componente da renda $k$, $\rho$ é a correlação entre um dos pares de componentes de renda, $S_{\kappa}$ é a proporção da renda familiar total que corresponde ao componente $k$, e $\mu_{\kappa}$ é a média de renda do componente $k$. O subscrito $f$ designa a renda familiar, $h$ designa a renda do trabalho dos homens (maridos), $m$ a renda do trabalho das mulheres (esposas), e $r$ a renda residual de todas as outras fontes. Em outras palavras, a desigualdade de renda familiar (mensurada pelo coeficiente de variação da renda familiar elevado ao quadrado, $\mathrm{CV}_{f}^{2}$ ) pode ser decomposta entre renda do trabalho de maridos, renda do trabalho de esposas e renda familiar residual. Cada uma destas três fontes de renda contribui de três formas para a desigualdade entre as famílias: (a) seu peso na renda familiar, (b) a desigualdade em sua própria distribuição e (c) suas correlações com as outras fontes. Para elaborar distribuições contrafatuais podemos definir um dos componen- 
Rendimento do Trabalho das Esposas e Tendências da Desigualdade de Renda...

tes da renda como sendo igual a zero (contrafatual 1) ou definir que um ou mais dos elementos de cada componente (proporção, correlação e/ou desigualdade em cada fonte) permaneçam sem mudar ao longo de algum período de tempo (contrafatuais 3 e 4). Usamos essa metodologia para analisar a contribuição dos rendimentos do trabalho das esposas para as tendências da desigualdade de renda entre os casais entre 1992 e 2014.

No entanto, para mostrar qual foi a contribuição dos rendimentos do trabalho das esposas para a desigualdade de renda entre todas as famílias, é fundamental definir dois tipos de famílias: as chefiadas por casais, com ou sem filhos ou outros parentes presentes, e outros tipos de família, cujos responsáveis são mulheres ou homens que não estão em união conjugal, vivendo com ou sem filhos ou outros parentes. A Equação 1 faz a decomposição entre as fontes de renda nas famílias com casais, distinguindo a contribuição de cada fonte para a desigualdade entre essas famílias. Mas, para saber exatamente qual a contribuição dos rendimentos das esposas para a desigualdade entre todas as famílias, é necessário um segundo tipo de operação: a decomposição entre grupos populacionais, que verifica em que medida a desigualdade dentro e entre os grupos - no nosso caso, os tipos de família - contribui para a desigualdade total. Para tanto, a primeira decomposição (Equação 1) deve ser combinada com a segunda (Equação 2 a seguir). Para realizar a decomposição entre famílias sem e com casais (grupos A e B respectivamente) usamos a seguinte fórmula (Cancian e Reed 1999; Chen, 2005):

$$
\text { (2) } \begin{array}{r}
C V_{t}^{2}=S_{A}\left(\mu_{A} / \mu\right)^{2} C V_{A}^{2}+S_{B}\left(\mu_{B} / \mu\right)^{2} C V_{B}^{2} \\
+\frac{S_{A}\left(\mu_{A} / \mu\right)^{2}+S_{B}\left(\mu_{B} / \mu\right)^{2}}{\mu^{2}}
\end{array}
$$

em que $C V_{t}^{2}$ é a desigualdade de renda entre todas as famílias; $S_{A}$ é a proporção de famílias no grupo $\mathrm{A} ; \mu$ é a média da renda total; $\mu_{\mathrm{A}}$ é a média de renda no grupo $\mathrm{A} ; \mathrm{e} C V_{A}^{2}$ é o coeficiente de variação da renda no grupo A. Na segunda Equação, utilizamos a desigualdade entre famílias com casais $\left(C V_{B}^{2}\right)$ calculada de acordo com a equação 1. Desta forma, podemos mensurar o impacto das mudanças na renda das esposas (contrafatuais 3 e 4) considerando a proporção de cada tipo de família e seu peso relativo na distribuição de renda. Para calcular os níveis de desigualdade contrafatuais em 2014 descontando as mudanças nas características da renda do trabalho das esposas, calculamos o coeficien-

DADOS - Revista de Ciências Sociais, Rio de Janeiro, vol. 61, nº 1, 2018 
te de variação ao quadrado das famílias com casais $\left(C V_{B}^{2}\right)$ com os valores da renda média e do coeficiente de variação das esposas - assim como as correlações envolvendo a renda das esposas no caso do contrafatual 4 - fixados em 1992 e todas as outras variáveis com valores de 2014. Também fazemos esses cálculos para dois outros períodos: 1992 a 2002, e 2003 a 2014. No primeiro desses períodos a queda da desigualdade de renda foi mais modesta, enquanto no segundo foi muito mais significativa.

\section{DADOS}

Utilizamos os dados da PNAD para o período de 1992 a 2014. Ao longo desse período, a PNAD não foi realizada apenas em 1994 e nos anos censitários de 2000 e 2010. Os domicílios da zona rural da Região Norte presentes a partir de 2004 foram excluídos para manter a comparabilidade com anos anteriores. Para a amostra de casais, selecionamos todos os domicílios chefiados por casais heterossexuais em que ambos os cônjuges tinham entre 25 e 55 anos. Escolhemos essa faixa etária porque queríamos garantir que a maioria tivesse finalizado seus estudos e também porque é o período do curso de vida em que as pessoas estão mais dedicadas ao mercado de trabalho. Os casais foram identificados pela condição dos indivíduos no domicílio, independentemente do tipo de união (casamento civil e/ou religioso ou união consensual). Em outras palavras, não fazemos distinção entre casamento e coabitação. Diferenças entre os tipos de união no que diz respeito ao trabalho das mulheres e à igualdade de gênero são questões que merecem ser investigadas, mas fogem ao escopo deste trabalho. Casais homossexuais não foram incluídos porque nossa discussão se refere a papéis de gênero e padrões de divisão do trabalho associados a relações heterossexuais. Além disso, casais homossexuais só foram registrados na PNAD a partir de 2007 e, até o final do período, totalizam menos de 500 casos na faixa etária escolhida.

Uma amostra ampliada de famílias, que utilizamos no cálculo dos contrafatuais 3 e 4 , inclui também os domicílios em que os responsáveis tinham entre 25 e 55 anos mas não havia cônjuge presente. Com o objetivo de evitar distorções causadas por valores extremos, excluímos também 177 domicílios (cerca de $0,01 \%$ da amostra ampliada) cuja renda per capita era superior a vinte desvios-padrão da média do respectivo ano. Desconsiderando ainda os casos com informações ausentes, 
nossa amostra inclui um total de 1.222.423 domicílios, sendo 867.318 deles chefiados por casais.

É importante notar que as unidades de análise são os domicílios, embora nos refiramos a domicílios e famílias de forma intercambiável. Os laços familiares evidentemente se estendem para além dos domicílios e parentes não residentes podem ter papel importante na renda domiciliar". Por outro lado, um domicílio pode comportar mais de uma "família" na definição das PNADs e Censos - por exemplo, um casal que vive com os pais de um dos cônjuges. Em todo caso, faz sentido analisar a distribuição de renda entre os domicílios porque eles constituem uma unidade fundamental de compartilhamento de recursos e despesas.

No cálculo do coeficiente de variação das famílias utilizamos a renda domiciliar per capita. Cada uma das fontes de renda domiciliar também foi dividida pelo número de moradores, de modo que os dois lados da Equação 1 estivessem na mesma escala. Isso significa que os resultados apresentados nas próximas seções se referem sempre à escala per capi$t a$, mesmo nas estatísticas univariadas. Por exemplo, as correlações foram calculadas entre os rendimentos per capita dos maridos e rendimentos per capita das esposas; $\mathrm{o} \mathrm{CV}^{2}$ de cada fonte de renda domiciliar é a razão entre o desvio padrão e a média da distribuição per capita da respectiva fonte em determinado ano; e assim por diante. Apesar de tornar a interpretação das tendências menos intuitiva, este procedimento garante que todos os componentes sejam controlados pelo tamanho do domicílio e viabiliza a decomposição da renda domiciliar per capita. Note-se que embora seja possível analisar as tendências dos rendimentos de maridos e esposas ignorando o tamanho do domicílio - visto que são rendas individuais - não é plausível fazer o mesmo com a renda residual, que agrega diferentes tipos de renda de um número variável de moradores. Não obstante as diferenças nos números absolutos, as tendências na escala per capita são praticamente idênticas às observadas com os valores originais ${ }^{5}$.

\section{COMPONENTES DA RENDA DOS CASAIS}

O impacto dos rendimentos das esposas depende tanto da distribuição desses rendimentos quanto das relações entre eles e as outras fontes de renda familiar. Em particular, há três componentes importantes: correlação entre rendimentos das esposas e outras fontes (e entre as outras fontes), desigualdade em cada fonte de renda e contribuição propor- 
Figura 2

Correlações entre Fontes de Renda Domiciliar

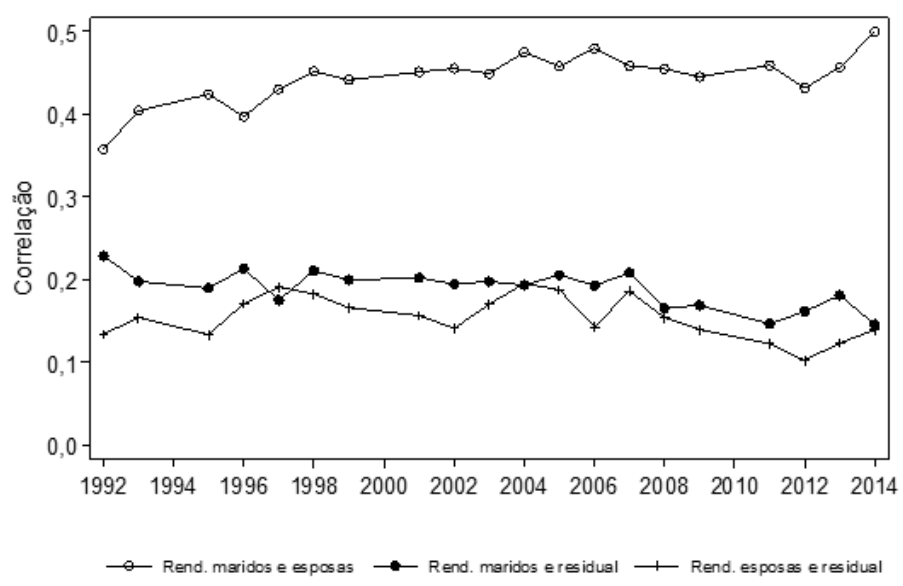

Fonte: Elaboração própria com dados das PNADs 1992-2014.

cional de cada fonte para renda familiar. As figuras 2, 3 e 4 apresentam as mudanças, entre 1992 e 2014, nestes componentes, que também estão especificados na Equação 1. A Figura 2 mostra mudanças na correlação entre os rendimentos de maridos e esposas e entre os de cada cônjuge e a renda residual (de todas as outras fontes). A correlação entre os rendimentos de maridos e esposas era de 0,36 em 1992 e passou a ser de 0,50 em 2014. De acordo com a Equação 1, um crescimento na correlação da renda dos casais, mantendo todos os outros componentes iguais, levaria a um aumento da desigualdade de renda entre as famílias. Embora a correlação não seja muito alta, não há dúvida de que há uma tendência significativa de aumento.

A Figura 3 mostra as tendências dos coeficientes de variação ao quadrado $\left(\mathrm{CV}^{2}\right)$ de 1992 até 2014. Tudo o mais constante, diminuições na desigualdade em qualquer um dos componentes da renda diminuiriam a desigualdade da renda familiar. De acordo com o coeficiente de variação das famílias $\left(C V_{f}^{2}\right)$ a desigualdade de renda entre famílias com casais diminuiu cerca de $32 \%$ ao longo do período. A desigualdade de renda entre os maridos $\left(C V_{h}^{2}\right)$ diminuiu $23 \%$, sendo que a maior queda se deu na década de 2000. Em contraste, o coeficiente de variação das esposas $\left(\mathrm{CV}_{m}^{2}\right)$ caiu constantemente ao longo dos anos chegando a diminuir cerca de $54 \%$; ou seja, aparentemente a queda na desigualdade entre as mulheres (esposas) é um componente bastante significativo na queda da desigualdade de renda familiar no período. 
Figura 3

Mudança Percentual no CV² das Fontes de Renda Domiciliar $(1992=100)$

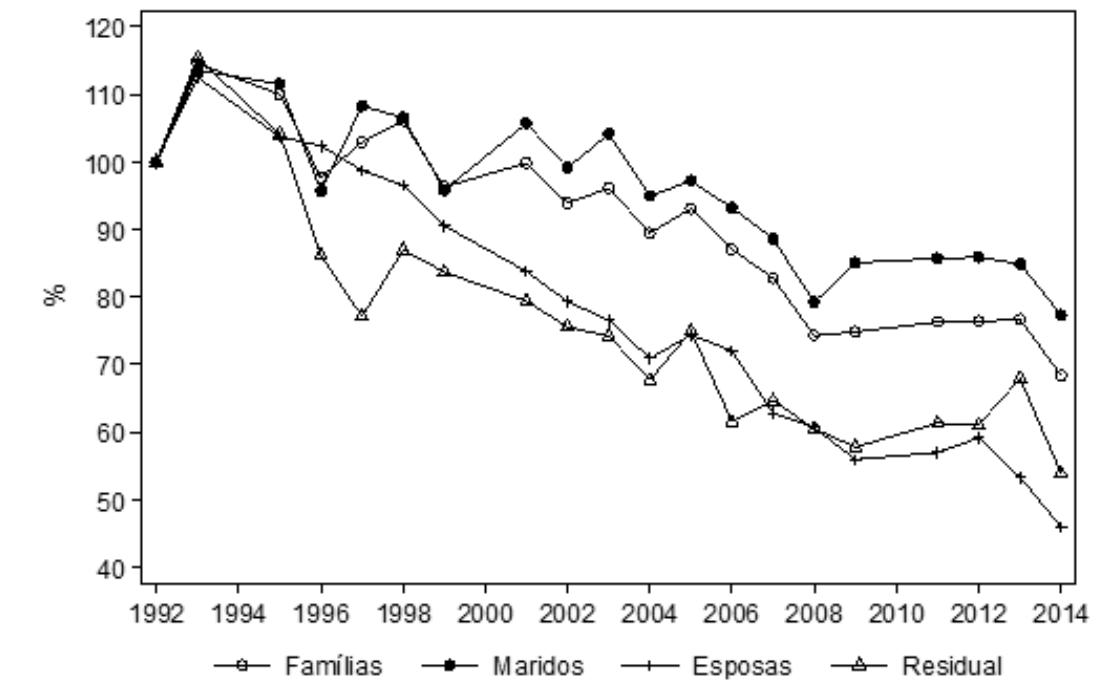

Fonte: Elaboração própria com dados das PNADs 1992-2014.

É importante notar que a tendência observada no $\mathrm{CV}^{2}$ das esposas é fruto de transformações tanto na família e na organização econômica das relações conjugais quanto na distribuição dos salários no mercado de trabalho: mais mulheres em união passaram a exercer trabalho remunerado e caiu a desigualdade entre as que têm alguma renda do trabalho. Apesar disso, a desigualdade entre as esposas permanece maior do que entre os maridos: em 2014 o coeficiente de variação elevado ao quadrado para os homens casados era de 2,30 e para as mulheres casadas era de 3,81 . Isso porque a proporção de esposas sem renda do trabalho é muito maior que a dos maridos. Quando consideramos apenas quem tem renda do trabalho, a desigualdade é menor entre as mulheres.

As proporções da renda familiar proveniente de cada fonte entre $1992 \mathrm{e}$ 2014 são apresentadas na Figura 4. A proporção da renda familiar correspondente aos rendimentos do trabalho das esposas aumentou constantemente ao longo dos anos: em 1992 era 16,6\% e em 2014 era 26,8\%. Consequentemente, a proporção devida ao rendimento do trabalho dos maridos diminuiu, passando de 65,6\% em 1992 para 57,5\% em 2014. A renda proveniente de outras fontes ficou entre $15 \%$ e $19 \%$ da renda familiar ao longo de todo o período.

DADOS - Revista de Ciências Sociais, Rio de Janeiro, vol. 61, no 1, 2018 
Figura 4

Proporção da Renda Domiciliar por Fonte

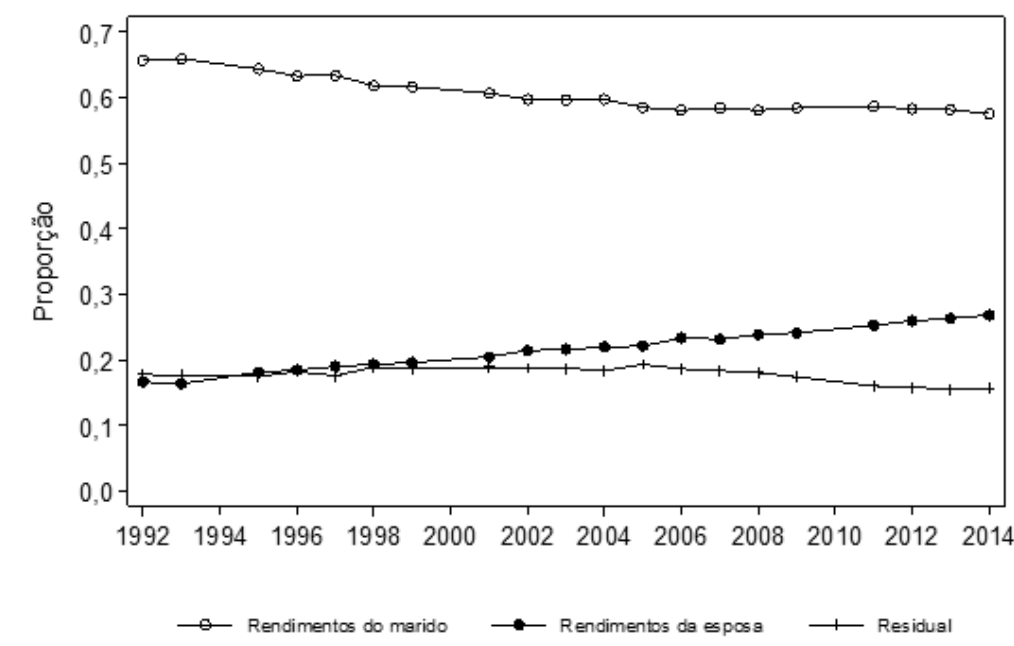

Fonte: Elaboração própria com dados das PNADs 1992-2014.

Tendo em vista que o coeficiente de variação é uma medida de desigualdade altamente decomponível, podemos verificar quais foram as contribuições de diferentes fontes para a desigualdade de renda. Para avaliar o efeito do rendimento do trabalho das esposas na tendência de queda da desigualdade de renda observada no Brasil nas duas últimas décadas, fizemos os quatro exercícios contrafatuais descritos acima, cujos resultados apresentamos a seguir.

\section{IMPACTO DOS RENDIMENTOS DO TRABALHO DAS ESPOSAS NA DESIGUALDADE DE RENDA ENTRE CASAIS EM UM MOMENTO DO TEMPO}

Para avaliar os dois primeiros contrafatuais elaboramos a Figura 5 e analisamos a distribuição de renda das famílias chefiadas por casais. Na próxima seção avaliaremos os impactos na renda dos casais e de todos os outros tipos de famílias. A Figura 5 mostra as mudanças esperadas no coeficiente de variação da renda dos casais em 1992 e em 2014 como função de uma mudança hipotética na proporção da renda dos casais devida aos rendimentos do trabalho da esposa. Ambas as curvas foram obtidas a partir da variação contrafatual da proporção de contribuição dos rendimentos do trabalho das esposas, mantendo todos os outros componentes do $\mathrm{CV}^{2}$ das famílias inalterados (ver Equação 1). 
$\mathrm{CV}^{2}$ da Renda Domiciliar per capita em Diferentes Níveis de Contribuição dos Rendimentos das Esposas

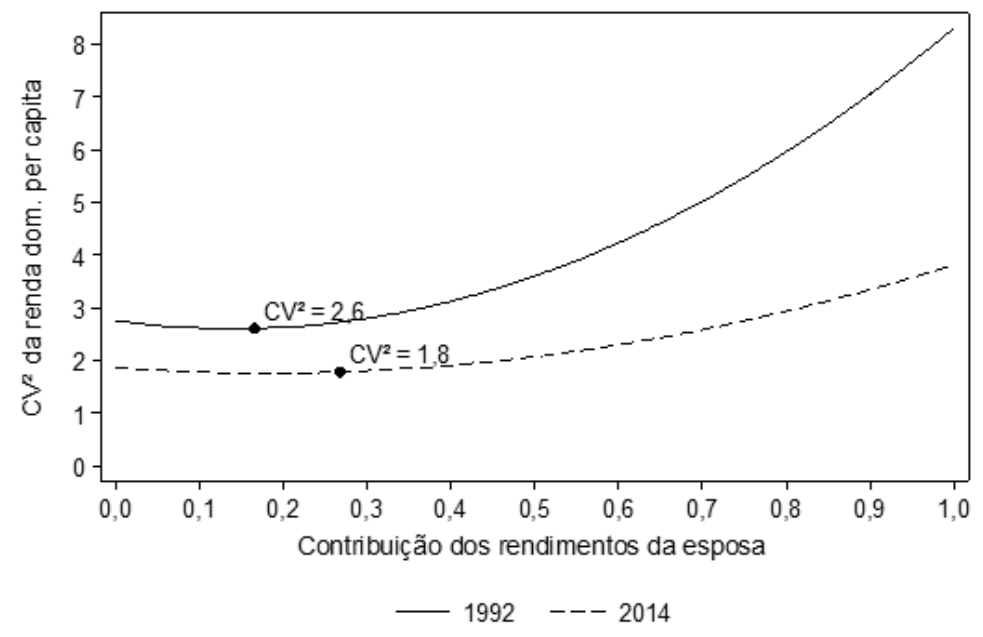

Fonte: Elaboração própria com dados das PNADs 1992-2014.

Nota: Os círculos indicam os valores observados em cada ano.

A curva para 1992 é mais acentuada e está acima da curva para 2014, o que significa que os componentes do coeficiente de variação levam a menos desigualdade em 2014 do que em 1992. Além disso, indicamos quais foram as proporções do rendimento das esposas e os coeficientes de variação observados em 1992 e 2014 (círculos e valores). Em ambas as curvas, a proporção observada dos rendimentos das esposas diminui um pouco as desigualdades em relação às que teriam sido observadas caso as proporções fossem zero. Isso ocorre porque estamos mantendo constantes os outros componentes do $\mathrm{CV}^{2}$ das famílias. Entre 1992 e 2014, os rendimentos das esposas e dos maridos se tornaram, por um lado, menos desiguais e, por outro, mais correlacionados. Estas características, combinadas com o aumento da proporção da renda das esposas, levariam ao aumento da desigualdade de renda entre os casais a partir de um determinado percentual de participação do rendimento das esposas na renda dos casais (quando as curvas da Figura 5 começam uma trajetória ascendente). Este ponto de inflexão se daria antes em 1992 do que em 2014, o que implica dizer que os componentes da desigualdade arrolados favorecem mais igualdade em 2014 do que em 1992. A seguir avaliamos especificamente os dois primeiros contrafatuais. 
O primeiro contrafatual compara a distribuição de renda observada em cada ano com a distribuição que teríamos verificado se as esposas tivessem renda zero, mantendo todos os outros elementos constantes. Na Figura 5, a desigualdade de renda entre casais obtida pelo contrafatual 1 pode ser observada pelo nível do coeficiente de variação ao quadrado da renda domiciliar per capita $\left(\mathrm{CV}^{2}\right)$ no eixo vertical quando a proporção do rendimento das esposas é igual a zero. Em 1992, o coeficiente de variação observado de 2,60 ocorreu quando a proporção do rendimento das esposas era de $16,6 \%$. Se as esposas não tivessem contribuído com nada (renda zero), e os outros componentes tivessem permanecido iguais, o coeficiente de variação da renda dos casais seria mais alto $(2,75)$, ou seja, teríamos observado uma desigualdade de renda familiar um pouco maior. Em outras palavras, os rendimentos do trabalho das esposas contribuíram, ainda que pouco, para diminuir as desigualdades em 1992. Em 2014 os rendimentos das esposas também tiveram um papel equalizador tendo em vista que o $\mathrm{CV}^{2}$ observado éligeiramente menor do que o que ocorreria caso a contribuição das esposas fosse zero. Em suma, a participação dos rendimentos das esposas na renda familiar tem, em maior ou menor medida, um efeito equalizador em todos os anos entre 1992 e 2014 - exceto em 1997, quando constatamos um ínfimo efeito de aumento da desigualdade.

O papel equalizador da participação das esposas ocorre porque seus rendimentos não estão perfeitamente correlacionados com as outras fontes de renda (marido e residual), por um lado, e apesar de a desigualdade entre as esposas ser maior do que entre os maridos, por outro lado. Isso também implica dizer que a proporção da renda dos maridos na renda total dos casais também teria um papel equalizador; ou seja, poderíamos elaborar um gráfico parecido com o da Figura 5 para a participação da renda dos maridos e chegaríamos a conclusões semelhantes - mas não idênticas - sobre sua participação na renda familiar ${ }^{6}$.

Assim, o contrafatual 1 permite responder a seguinte pergunta: “Qual seria o tamanho da desigualdade se as esposas não tivessem rendimentos?" Tanto em 1992 quanto em 2014 a desigualdade seria ligeiramente maior. Podemos, no entanto, fazer uma pergunta mais realista, tendo em vista que uma mudança tão radical (por exemplo, de $16 \%$ para $0 \%$ de participação em 1992) jamais ocorreria. Uma mudança marginal é mais plausível, uma vez que algum tipo de comportamento ou política poderia ter aumentado ou diminuído um pouco a contribuição das esposas em cada ano estudado. Por isso o contrafatual 2 
Rendimento do Trabalho das Esposas e Tendências da Desigualdade de Renda...

procura responder a seguinte pergunta: “Qual seria o tamanho da desigualdade se houvesse uma mudança marginal da contribuição dos rendimentos das esposas para a renda familiar?"

A avaliação do impacto desse tipo de mudança também pode ser feita a partir da interpretação das curvas apresentadas na Figura 5. As duas marcas representando os $\mathrm{CV}^{2}$ s observados em 1992 e 2014 se encontram próximas ao ponto mínimo de cada curva. Isso significa que uma pequena queda ou aumento da contribuição do rendimento das esposas não levaria a alterações significativas da desigualdade.

A comparação entre os contrafatuais 1 e 2 nos permite dizer, portanto, que mudanças marginais na participação dos rendimentos das esposas na renda total não teriam efeitos grandes no nível de desigualdade, mas mudanças para percentuais significativamente menores ou maiores levariam a mais desigualdade. O problema com os contrafatuais $1 \mathrm{e}$ 2 é que eles não permitem avaliar os impactos das mudanças na distribuição de rendimentos do trabalho das esposas nas tendências de desigualdade. Os impactos em um ponto do tempo parecem, no entanto, pequenos. A seguir avaliamos o efeito das mudanças na distribuição dos rendimentos das esposas na tendência de queda da desigualdade. Como veremos, estes impactos são maiores e mais importantes.

\section{IMPACTOS DAS MUDANÇAS AO LONGO DO TEMPO NOS RENDIMENTOS DO TRABALHO DAS ESPOSAS NA DISTRIBUIÇÃO DE RENDA DAS FAMÍLIAS}

Nesta seção, procuramos responder a seguinte pergunta: "Será que as mudanças nos rendimentos do trabalho das mulheres casadas ajudam a explicar a diminuição na desigualdade de renda entre os casais e as famílias nas duas últimas décadas?". Há um artigo anterior (Barros e Mendonça, 1989) que calculou o efeito do rendimento das esposas na desigualdade de renda familiar em 1985 e outro mostrando o efeito do crescimento da participação feminina no mercado de trabalho na desigualdade de renda entre 1981 e 2002 (Hoffmann e Leone, 2004; ver, também, Scorzafave e Menezes-Filho, 2005). Mas não há estudos mostrando os efeitos das mudanças nos rendimentos das esposas ao longo do tempo nas tendências de desigualdade e tampouco estudos analisando o impacto da renda das esposas no período de queda da desigualdade que se iniciou em meados dos anos 1990.

DADOS - Revista de Ciências Sociais, Rio de Janeiro, vol. 61, nº 1, 2018 
Usamos dois contrafatuais para calcular o nível de desigualdade que teria ocorrido se os rendimentos do trabalho das esposas não tivessem se modificado no período estudado. Primeiro, comparamos o $\mathrm{CV}^{2}$ das famílias com casais observado com aquele que teria ocorrido se a média e a desigualdade $\left(C V_{m}^{2}\right)$ dos rendimentos das esposas não tivessem se modificado (contrafatual 3). Fazemos a mesma comparação para a renda de todas as famílias (com e sem casais). Segundo, comparamos o nível de desigualdade observado (entre as famílias com casais e entre todos os tipos de família) com aquele que teria ocorrido caso a média, a desigualdade $\left(C V_{m}^{2}\right)$ e as correlações dos rendimentos das esposas com outras fontes não tivessem se modificado ao longo dos anos (contrafatual 4). Em ambos os casos, se a desigualdade observada for menor do que aquela que teria ocorrido se não houvesse mudanças nos rendimentos das esposas podemos concluir que as esposas desempenharam um papel equalizador e saber o quanto da diminuição da desigualdade se deve às mudanças nos rendimentos das esposas.

Dessa forma, usamos a Equação 2 para decompor a desigualdade entre casais e outros tipos de família e a Equação 1 para decompor a desigualdade dos casais entre as fontes de renda familiar. Calculamos o nível contrafatual de desigualdade em 2014 fixando, na Equação 1, a média e o $C V^{2}$ dos rendimentos das esposas (e as correlações para o contrafatual 4) em seus valores de 1992, com todas as outras variáveis nos níveis de 2014. De forma semelhante, calculamos os níveis contrafatuais de desigualdade para os subperíodos de 1992 a 2002, e 2003 a 2014.

Nas duas primeiras partes da Tabela 1 apresentamos os resultados das simulações para o contrafatual 3 para a amostra de casais e para todas as famílias. Em 1992 o CV² da renda total dos casais era 2,60 e em 2014 era 1,78 . Nesse período houve uma diminuição de $-0,82$ pontos (ver terceira coluna da tabela), o que corresponde a uma queda de $31,5 \%$ no índice de desigualdade. Se a média e o $\mathrm{CV}^{2}$ do rendimento das esposas tivessem se mantido com o mesmo valor de 1992 ao longo de todo o período e todos os outros componentes da desigualdade de renda tivessem se modificado (i.e., chegado ao valor que tinham em 2014) o $\mathrm{CV}^{2}$ da renda total dos casais teria sido de 1,96 em 2014 (coluna 4 da Tabela 1). Ou seja, as mudanças na renda das esposas reduziram o $C V^{2}$ da renda dos casais em 0,17 (coluna 5): em vez de $1,78, \mathrm{o} \mathrm{CV}^{2}$ dos casais seria de 1,96 em 2014 e a queda da desigualdade teria sido de $24,6 \%$ em vez de $31,5 \%$. Em outras palavras, se os rendimentos das esposas não tives- 
Rendimento do Trabalho das Esposas e Tendências da Desigualdade de Renda...

sem aumentado sua média e diminuído sua desigualdade interna, a queda na desigualdade de renda entre os casais no período de 1992 a 2014 teria sido cerca de $22 \%$ menor do que a de fato observada. Estas duas características do rendimento das esposas tiveram, portanto, um papel equalizador no período de 1992 a 2014

Tabela 1

Impacto das Mudanças na Distribuição de Rendimentos do Trabalho das Esposas na Desigualdade de Renda entre Famílias Chefiadas por Casais e entre todos os Tipos de Família

\begin{tabular}{cccccc}
\hline & $\begin{array}{c}\mathbf{C V}^{2} \\
\text { Observado } \\
\text { Ano 1 } \\
\text { (1) }\end{array}$ & $\begin{array}{c}\mathbf{C V}^{\mathbf{2}} \\
\text { Observado } \\
\text { Ano 2 } \\
\mathbf{( 2 )}\end{array}$ & $\begin{array}{c}\text { Mudança } \\
\mathbf{C V}^{2} \\
\text { Observado } \\
\mathbf{( 2 )}-\mathbf{( 1 )}\end{array}$ & $\begin{array}{c}\mathbf{C V}^{2} \\
\text { Contra- } \\
\text { fatual } \\
\mathbf{( 4 )}\end{array}$ & $\begin{array}{c}\text { Mudança } \\
\text { devida às } \\
\text { esposas } \\
\mathbf{( 2 )}-\mathbf{( 4 )}\end{array}$ \\
\hline Contrafatual 3 & & & & & \\
Casais & & & & & \\
1992-2014 & 2,60 & 1,78 & $-0,82$ & 1,96 & $-0,17$ \\
1992-2002 & 2,60 & 2,45 & $-0,16$ & 2,50 & $-0,05$ \\
2003-2014 & 2,51 & 1,78 & $-0,72$ & 1,93 & $-0,15$ \\
Todas as famílias & & & & & \\
1992-2014 & 2,90 & 2,08 & $-0,82$ & 2,18 & $-0,10$ \\
1992-2002 & 2,90 & 2,92 & 0,02 & 2,95 & $-0,03$ \\
2003-2014 & 2,81 & 2,08 & $-0,73$ & 2,17 & $-0,09$ \\
Contrafatual 4 & & & & & \\
Casais & & & & & \\
1992-2014 & 2,60 & 1,78 & $-0,82$ & 1,86 & $-0,07$ \\
1992-2002 & 2,60 & 2,45 & $-0,16$ & 2,41 & 0,04 \\
2003-2014 & 2,51 & 1,78 & $-0,72$ & 1,90 & $-0,12$ \\
Todas as famílias & & & & & $-0,04$ \\
1992-2014 & 2,90 & 2,08 & $-0,82$ & 2,12 & 0,02 \\
1992-2002 & 2,90 & 2,92 & 0,02 & 2,90 & $-0,07$ \\
2003-2014 & 2,81 & 2,08 & $-0,73$ & 2,15 &
\end{tabular}

Fonte: Elaboração própria com dados das PNADs 1992-2014.

Nota: $C^{2}$ é o coeficiente de variação elevado ao quadrado. Os resultados nas colunas 3 e 5 foram calculados com mais decimais do que os apresentados nas colunas 1, 2 e 4 e por isso podem diferir dos obtidos com os valores arredondados.

Como mencionamos acima dividimos o período em duas partes para entender melhor a dinâmica da mudança. Entre 1992 e 2002 a queda na desigualdade total foi menor, passando de 2,60 para 2,45 - uma diminuição de aproximadamente $6 \%$. Caso o rendimento das esposas não

DADOS - Revista de Ciências Sociais, Rio de Janeiro, vol. 61, nº 1, 2018 
tivesse se modificado (média e $\mathrm{CV}^{2}$ permanecessem no patamar de 1992) a queda teria sido ainda menor, na medida em que o $C V^{2} \mathrm{em} 2002$ seria 2,50. Assim, na primeira década analisada o rendimento das esposas contribuiu em 0,05 pontos para a queda da desigualdade, o que representa cerca de um terço da modesta queda total do período. Em contraste, na segunda década a desigualdade de renda entre casais passou de 2,51 em 2003 para 1,78 em 2014, ou seja, a desigualdade ficou $29 \%$ menor. O exercício contrafatual (3) revela que caso o rendimento das esposas tivesse permanecido com a média e o $\mathrm{CV}^{2}$ de 2003 a desigualdade total em 2014 seria de 1,93; ou seja, seria maior em 0,15 do que a de fato observada. A queda da desigualdade nessa década seria, portanto, de apenas $23 \%$, em vez de $29 \%$. Em suma, a diminuição na desigualdade de renda entre as esposas e o aumento da média de sua renda desempenharam um forte papel equalizador principalmente a partir de 2003, embora tenham tido este papel ao longo de todo o período que vai de 1992 a 2014.

Os rendimentos das esposas também tiveram um impacto equalizador na queda da desigualdade de renda entre todos os tipos de família (com e sem casais) - ainda que, como era de se esperar, o efeito tenha sido menor do que entre apenas as famílias com casais. Se a média e o $\mathrm{CV}^{2}$ da distribuição das esposas não tivesse se modificado entre $1992 \mathrm{e}$ 2014, o CV² para todas as famílias teria passado de 2,9 em 1992 para 2,18 em 2014 (valor contrafatual) em vez do valor de fato observado de 2,08 . Em outras palavras, o aumento da contribuição dos rendimentos das esposas e a queda na desigualdade entre esposas contribuíram em 0,10 para diminuir a desigualdade entre 1992 e 2014 . A queda da desigualdade entre todas as famílias foi de $28 \%$, mas teria sido de $25 \%(11 \%$ menor) se essas características dos rendimentos das esposas não tivessem se modificado. A maior parte dessa contribuição se deu entre 2003 e 2014, como indicamos na Tabela 1.

Na terceira e na quarta parte da Tabela 1 apresentamos os resultados das análises (contrafatual 4) que adicionam ao contrafatual 3 as mudanças nas correlações entre os rendimentos de maridos e esposas e entre os rendimentos das esposas e a renda residual das famílias. As diferenças em relação ao contrafatual 3 se devem principalmente a mudanças na correlação entre os rendimentos dos cônjuges, porque estes rendimentos contribuem com uma porcentagem muito maior da renda dos casais do que a renda residual. Este fato também fica claro quando inspecionamos a Figura 4 e observamos a crescente participa- 
Rendimento do Trabalho das Esposas e Tendências da Desigualdade de Renda...

ção dos rendimentos das esposas e a relativamente estável participação da renda residual como componentes da renda das famílias com casais. Além disso, a Figura 2 mostra que a correlação entre os rendimentos de maridos e esposas aumentou entre 1992 e 2014, enquanto a correlação dos rendimentos das esposas com a renda residual, apesar de alguma variação, estava no mesmo patamar no início do período e em 2014.

De fato, as análises usando o contrafatual 4 mostram que, entre 1992 e 2014, as correlações envolvendo os rendimentos das esposas com as outras duas fontes (maridos e residual) diminuem o papel equalizador dos rendimentos das esposas em relação ao contrafatual 3. Ou seja, enquanto o contrafatual 3 (fixando a média e o $\mathrm{CV}^{2}$ do rendimento das esposas nos níveis de 1992) fazia com que a desigualdade entre os casais diminuísse 0,17 menos do que de fato diminuiu, fixar também as correlações dos rendimentos das esposas com as outras fontes de renda faz com que a desigualdade diminua cerca de 0,07 menos do que de fato caiu. Em outras palavras, o aumento da correlação entre os rendimentos dos cônjuges diminuiu o efeito equalizador das mudanças nos rendimentos das esposas entre 1992 e 2014.

Esse "freio" na tendência de queda da desigualdade é mais forte entre 1992 e 2002, tendo em vista que nesse período a desigualdade teria diminuído um pouco mais do que de fato diminuiu - passando de 2,60 em 1992 para 2,41 em 2002, em vez de 2,45 nesse último ano - caso a correlação entre os rendimentos das esposas com as outras fontes não tivesse aumentando. Entre 2003 e 2014 as correlações também tiveram um papel não equalizador, mas seu efeito foi um pouco menos acentuado. Em suma, o efeito líquido das mudanças na média e $\mathrm{CV}^{2}$ das esposas e na correlação entre as rendas dos cônjuges foi equalizador entre 1992 e 2014, mas esses três elementos (média, CV² e correlação) atuaram em sentidos diferentes.

A quarta parte da Tabela 1 mostra novamente, dessa vez com o contrafatual 4, que os rendimentos das esposas têm um efeito menor na renda de todas as famílias do que na renda dos casais. No primeiro período, 1992 a 2002, as mudanças nos rendimentos das mulheres aumentaram ligeiramente a desigualdade: $\mathrm{o} \mathrm{CV}^{2}$ da renda de todas as famílias teria sido 0,02 menor se o rendimento das esposas e sua correlação com outras fontes tivessem permanecido nos níveis de 1992. Mas também

DADOS - Revista de Ciências Sociais, Rio de Janeiro, vol. 61, nº 1, 2018 
para todas as famílias o efeito líquido, ainda que modesto, foi de diminuição da desigualdade entre 1992 e 2014.

Os resultados apresentados na Tabela 1 mostram que, se os rendimentos das esposas não tivessem se modificado ao longo dos 22 anos estudados, a queda da desigualdade de renda teria sido até $22 \%$ menor do que de fato foi. As mudanças nos rendimentos das esposas desempenharam um papel equalizador que se somou à tendência geral de diminuição da desigualdade registrada para o período.

\section{CONCLUSÃO}

As análises apresentadas neste artigo permitiram mostrar que as mudanças na distribuição do rendimento do trabalho das mulheres em união conjugal contribuíram significativamente para a tendência de queda da desigualdade de renda entre 1992 e 2014. Dois fatores foram fundamentais: a diminuição da desigualdade entre as mulheres em união e o aumento proporcional, em relação aos homens casados, da renda dessas mulheres. Um terceiro aspecto importante é a correlação dos rendimentos das esposas com os rendimentos de seus maridos. Esta correlação aumentou ao longo dos anos e contribuiu para diminuir o efeito equalizador do rendimento das esposas. Os efeitos destes três aspectos estão relacionados, por um lado, a mudanças mais amplas que ocorreram no mercado de trabalho e que contribuíram para a diminuição da desigualdade de rendimentos do trabalho em geral, e, por outro lado, a mudanças nas famílias que passaram a contar crescentemente com os rendimentos das esposas. As mudanças no mercado de trabalho já foram amplamente analisadas em diversos trabalhos sobre as tendências da desigualdade no Brasil, enquanto os efeitos de mudanças nas famílias nessas tendências foram menos exploradas por cientistas sociais.

Nossas análises, bem como outras anteriores (Hoffmann e Leone, 2004), mostram claramente que o aumento da participação feminina no mercado de trabalho e as mudanças na distribuição do rendimento das mulheres solteiras e casadas estão relacionados às tendências da desigualdade de renda. Os rendimentos das mulheres foram afetados pelos mesmos fatores que explicam a queda da desigualdade dos rendimentos do trabalho dos homens. Embora não tenhamos analisado estes aspectos, sabemos que a desigualdade nos rendimentos do trabalho diminuiu principalmente porque: (1) aumentou a escolaridade da 
Rendimento do Trabalho das Esposas e Tendências da Desigualdade de Renda...

população, e (2) aumentou o salário mínimo. Políticas públicas de transferência de renda (Bolsa Família, por exemplo) não afetam diretamente a distribuição dos rendimentos do trabalho, mas apenas a distribuição de outras rendas, às quais chamamos aqui de renda familiar residual e que não foram foco de nossas análises. Sendo assim, podemos dizer que a queda na desigualdade dos rendimentos do trabalho das mulheres também foi afetada pela ampliação da escolaridade e pela apreciação real do salário mínimo. No caso das mulheres casadas, estes efeitos se combinam ao aumento de sua participação no mercado de trabalho, que, como mencionamos acima, foi mais intenso entre aquelas cujos maridos tinham rendimentos acima da mediana (ver nota 1 ). A entrada destas mulheres, no entanto, nos remete a mudanças dentro das famílias que foram fundamentais para explicar as tendências observadas.

Os principais indicadores que apresentamos sobre as mudanças no papel das mulheres casadas dentro das famílias são o aumento de sua participação no mercado de trabalho e o aumento da proporção da renda das famílias com casais que se deve aos rendimentos das esposas. Tais mudanças também levaram a um aumento da correlação entre as rendas de maridos e esposas. De acordo com a teoria proposta por Oppenheimer (1988) e Sweeney (2002), esse tipo de mudança é um indicador de que os casais estariam adotando um modelo mais colaborativo em que ambos os cônjuges contribuem com renda e com trabalho doméstico. Sabemos que ainda há muita desigualdade em termos de trabalho doméstico, tendo em vista que as mulheres trabalham mais do que os homens quando somamos trabalho doméstico à atividade no mercado de trabalho (Pinheiro e Medeiros, 2016). De qualquer forma, os dados e análises que apresentamos indicam que cada vez mais as famílias contam com a contribuição financeira de ambos os cônjuges. Estas mudanças aumentam, de acordo com Oppenheimer (1988), a importância da posição das mulheres no mercado de trabalho como determinantes do casamento, e sugerem fortemente que o modelo de especialização e troca de Becker (1974) não é adequado para explicar os aspectos financeiros e econômicos dos casamentos contemporâneos. Nossas análises confirmam estas expectativas para o Brasil, e sugerem que mudanças na estrutura familiar contribuíram para a diminuição da desigualdade.

Os exercícios contrafatuais que desenvolvemos indicam claramente que a queda da desigualdade no rendimento do trabalho das esposas e

DADOS - Revista de Ciências Sociais, Rio de Janeiro, vol. 61, nº 1, 2018 
o aumento proporcional de seus rendimentos exerceram um forte papel equalizador. Cerca de $22 \%$ da queda na desigualdade entre as famílias chefiadas por casais e cerca de $11 \%$ da queda entre todas as famílias se deve às mudanças nos rendimentos das esposas. Também mostramos que o aumento da correlação entre os rendimentos de maridos e esposas diminui o efeito equalizador da renda das mulheres. Essa última conclusão sugere que a relação entre os rendimentos dos cônjuges deve ser investigada em mais detalhe. O coeficiente de correlação apresentado aqui é um indicador sintético que não leva em conta a estrutura de associação. Modelos mais sofisticados podem ser usados para destrinchar as características da associação entre os rendimentos dos cônjuges (Schwartz, 2010) e esse deve ser o foco de análises futuras.

(Recebido para publicação em 17 de Agosto de 2016)

(Aprovado em 17 de Outubro de 2017) 
Rendimento do Trabalho das Esposas e Tendências da Desigualdade de Renda...

\section{NOTAS}

1. Ao longo do período analisado neste artigo, a participação das esposas no mercado de trabalho cresceu proporcionalmente mais entre o sexto e o oitavo decil dos rendimentos dos maridos. Essas estatísticas não são apresentadas em detalhes aqui, mas estão disponíveis mediante solicitação aos autores.

2. A situação conjugal independe do estado civil e, no caso da Figura 1, foi definida pela condição na família, e não no domicílio, como no resto das análises (ver seção intitulada Dados).

3. Esses domicílios - incluindo ou não outros parentes - representavam $67 \%$ da nossa amostra em 2014

4. As PNADs do período estudado registram doações normalmente recebidas de não moradores entre as rendas não oriundas do trabalho.

5. Esses resultados podem ser obtidos mediante solicitação aos autores.

6. Fizemos esses cálculos mas não os apresentamos aqui por falta de espaço. Eles podem ser obtidos mediante solicitação aos autores. 


\section{REFERÊNCIAS BIBLIOGRÁFICAS}

BARROS, Ricardo Paes de; MENDONÇA, Rosane S. Pinto. (1989), “Família e Distribuição de Renda: O Impacto da Participação das Esposas no Mercado de Trabalho". Pesquisa e Planejamento Econômico, vol. 19, no 3, pp. 483-504.

BARROS, Ricardo Paes de; FOGUEL, Miguel Nathan; ULYSSEA, Gabriel. (2007), Desigualdade de Renda no Brasil: Uma Análise da Queda Recente. Brasília, Ipea, volumes 1 e 2.

BECKER, Gary. (1974), "A Theory of Marriage”, in T. W. Schultz (ed.), Economics of the Family: Marriage, Children and Human Capital. Chicago, University of Chicago Press.

_ _ LANDES, Elisabeth M.; MICHAEL, Robert T. (1977), “An Economic Analysis of Marital Instability". Journal of Political Economy, vol. 85, no 6, pp. 1141-1187.

CANCIAN, Maria; REED, Deborah. (1999), “The Impact of Wives' Earnings on Income Inequality: Issues and Estimates". Demography, vol. 36, no 2, pp. 173-184.

CARVALHAES, Flavio; et al. (2014), “Os Impactos da Geração de Empregos sobre as Desigualdades de Renda: Uma Análise da Década de 2000." Revista Brasileira de Ciências Sociais, vol. 29, no 85, pp. 79-98.

CHEN, Yuanyuan. (2005), The Impact of Agricultural and Industrial Development on Income Inequality in Rural China. Mimeo.

FERREIRA, Francisco H. G.; et al. (2006), “Ascensão e Queda da Desigualdade de Renda no Brasil”. Econômica, vol. 8, no 1, pp. 147-169.

HOFFMANN, Rodolfo; LEONE, Eugênia Troncoso. (2004), “Participação da Mulher no Mercado de Trabalho e Desigualdade da Renda Domiciliar per Capita no Brasil: 1981-2002." Nova Economia, vol.14, no 2, pp. 35-58.

IBGE (INSTITUTO BRASILEIRO DE GEOGRAFIA E ESTATÍSTICA). (2010), Censo Demográfico 2010: famílias e domicílios: resultados da amostra. Rio de Janeiro: IBGE.

ITABORAÍ, Nathalie Reis. (2015), Mudanças nas Famílias Brasileiras (1976-2012): Uma Perspectiva de Classe e Gênero. Tese (Doutorado em Sociologia), Instituto de Estudos Sociais e Políticos, Universidade do Estado do Rio de Janeiro, Rio de Janeiro.

LANGONI, Carlos. (2005), Distribuição de Renda e Desenvolvimento Econômico no Brasil. 3 a ed. Rio de Janeiro, Editora FGV.

MEDEIROS, Marcelo; SOUZA, Pedro H. G Ferreira de; CASTRO, Fabio Avila de. (2015), “O Topo da Distribuição de Renda no Brasil: Primeiras Estimativas com Dados Tributários e Comparação com Pesquisas Domiciliares (2006-2012)". DADOS - Revista de Ciências Sociais, vol. 58, no 1, pp. 7-36.

MENEZES-FILHO, Naercio; OLIVEIRA, Alison Pablo. (2014), “A Contribuição da Educação para a Queda da Desigualdade de Renda per Capita no Brasil". Insper, Policy Paper no 9.

MENEZES-FILHO, Naercio; RODRIGUES, Eduardo A. de S. (2009), "Salário Mínimo e Desigualdade no Brasil, 1981-1999: Uma Abordagem Semiparamétrica". Revista Brasileira de Economia, vol. 63, no 3, pp. 277-298.

OPPENHEIMER, Valerie Kincade. (1988), "A Theory of Marriage Timing”. American Journal of Sociology, vol. 94, no 3, pp. 563-591. 
Rendimento do Trabalho das Esposas e Tendências da Desigualdade de Renda...

PINHEIRO, Luana S.; MEDEIROS, Marcelo. (2016), “Desigualdades de Gênero em Tempo de Trabalho Pago e Não Pago no Brasil, 2013". IPEA, Texto para discussão n-2214.

RIBEIRO, Carlos Antonio Costa. (2014), “Desigualdade nas Transições para a Vida Adulta no Brasil (1996 e 2008)". Sociologia \& Antropologia, vol. 4, no 2, pp. 433-473.

SCHWARTZ, Christine. (2010), "Earnings Inequality and the Changing Association between Spouses' Earnings". American Journal of Sociology, vol. 115, o 5, pp. 1524-1557.

SCORZAFAVE, Luiz Guilherme; MENEZES-FILHO, Naercio Aquino. (2005), “Impacto da Participação das Mulheres na Evolução da Distribuição de Renda do Trabalho no Brasil". Pesquisa e Planejamento Econômico, vol. 35, no 2, pp. 245-266.

SEDLACEK, Guilherme Luís; SANTOS, Eleonora Cruz. (1991), "A Mulher Cônjuge no Mercado de Trabalho como Estratégia de Geração da Renda Familiar". Ipea, Texto para Discussão nำ209.

SHORROCKS, Anthony F. (1983), "The Impact of Income Components on the Distribution of Family Incomes". The Quarterly Journal of Economics, vol. 98, no2, pp. 311-326.

SOARES, Sergei S. D. (2002), “O Impacto Distributivo do Sala’rio Mi’nimo: A Distribuição Individual dos Rendimentos do Trabalho". Ipea, Texto para Discussa o n. 873.

SOUZA, Pedro H. G. F.; CARVALHAES, Flavio. (2014), “Estrutura de Classes, Educação e Queda da Desigualdade de Renda (2002-2011)". DADOS - Revista de Ciências Sociais, vol. 57, no 1, pp. 101-128.

SWEENEY, Megan. (2002), "Two Decades of Family Change: The Shifting Economic Foundations of Marriage". American Sociological Review, vol. 63, no 1, pp. 132-147.

WAJNMAN, Simone; TURRA, Cassio; AGOSTINHO, Cintia S. (2007), “Estrutura Domiciliar e Distribuição da Renda Familiar no Brasil", in R. P. de Barros et al. (orgs.), Desigualdade de Renda no Brasil: Uma Análise da Queda Recente. Brasília, Ipea.

DADOS - Revista de Ciências Sociais, Rio de Janeiro, vol. 61, nº 1, 2018 
Carlos Antonio Costa Ribeiro e Weverthon Machado

\section{RESUMO}

Rendimento do Trabalho das Esposas e Tendências da Desigualdade de Renda no Brasil (1992-2014)

Nas últimas décadas, as mulheres que viviam em união conjugal foram as principais responsáveis pelo aumento da participação feminina no mercado de trabalho no Brasil. Isso se traduziu na crescente contribuição dos rendimentos do trabalho das esposas para a renda das famílias. Neste artigo, argumentamos que essas tendências ajudaram a diminuir a desigualdade de renda entre as famílias desde a década de 1990. Usando dados das PNADs, decompomos a desigualdade da renda domiciliar per capita, medida pelo coeficiente de variação ao quadrado, segundo: a) fontes da renda domiciliar (rendimentos do trabalho do marido, rendimentos do trabalho da esposa e outras rendas); e b) tipos de família (chefiadas por casais ou não). A partir dessas decomposições desenvolvemos análises contrafactuais para verificar o impacto dos rendimentos do trabalho das esposas nas tendências da desigualdade de renda no Brasil entre 1992 e 2014. Apesar do aumento da associação entre os rendimentos dos cônjuges, o efeito líquido das mudanças nos rendimentos das esposas durante o período analisado foi equalizador.

Palavras-chave: desigualdade de renda; famílias; trabalho feminino; casamentos; mercado de trabalho

\section{ABSTRACT \\ Female Laborforce Participation and Tendencies Affecting Income Inequality in Brazil (1992-2014)}

Women living with their spouses have served as the main sector of society driving the increase in female laborforce participation in Brazil in recent decades. Such a phenomenon is reflected in the growing contribution made by women to family income levels. The following article argues that such trends have helped to reduce income inequality among families as of the 1990s. Harnessing data from the PNADs (Brazilian National Household Surveys), we examine household income inequality per capita, measured by the coefficient of variation squared, according to a) sources of household income (husband's earnings, wife's earnings and other income); and b) family type (whether or not the family is headed by a couple or not). We use this information to develop counterfactual analyses to examine the impact of women's earnings on income inequality trends in Brazil from 1992 to 2014. With the growing parity of earnings between spouses, the net result of the shifts in women's earnings during the period under analysis had a balancing effect.

Key words: income inequality; families; female laborforce participation; marriages; labor market 


\section{RÉSUMÉ}

Revenus du Travail des Épouses et Tendances des Inégalités de Revenus au Brésil (1992-2014)

Lors des dernières décennies, les femmes vivant en union conjugale ont été les principales responsables de l'augmentation de la participation féminine au marché du travail brésilien. Cela s'est traduit par la contribution croissante des revenus du travail des épouses au revenu des familles. Dans cet article, nous défendrons l'argument de ce que ces tendances ont contribué à faire diminuer les inégalités de revenus parmi les familles depuis les années 1990. Sur la base de données des PNAD (enquêtes domiciliaires), nous avons décomposé les inégalités de revenu des ménages per capita, mesurées par le coefficient de variation au carré, selon : a) les sources de revenu des ménages (revenus du travail de l'époux, revenus du travail de l'épouse et autre revenus) ; et b) les types de familles (dirigées par des couples ou non). Sur cette base, nous avons développé des analyses contrefactuelles pour vérifier l'impact des revenus du travail des épouses sur les tendances des inégalités de revenus au Brésil entre 1992 et 2014.

Mots-clés: inégalités de revenus; familles; travail féminin; mariages; marché du travail

\section{RESUMEN}

Los Ingresos Laborales de las Mujeres Casadas y las Tendencias de las Desigualdades Económicas en Brasil (1992-2014)

En las últimas décadas, las mujeres que vivían en unión conyugal fueron las principales responsables del aumento de la participación femenina en el mercado laboral brasileño. Esta realidad se tradujo en una creciente contribución de los ingresos laborales que obtenían las mujeres a la situación económica de las familias. En este artículo, argumentamos que esas tendencias ayudaron a disminuir las desigualdades de ingresos entre las familias desde la década de 1990. Tomando como base los datos de las Encuestas Nacionales por Muestra de Domicilios (PNAD) del Instituto Nacional de Estadística de Brasil, desglosamos las desigualdades de los ingresos per cápita por hogar, medidas por el coeficiente de variación al cuadrado, según: a) fuentes de ingresos familiares (ingresos laborales del marido, ingresos laborales de la mujer y otros ingresos); e b) tipos de familias (encabezadas por matrimonios o no). A partir de estos desgloses, desarrollamos análisis contrafactuales para comprobar el impacto de los ingresos laborales de las mujeres casadas en las tendencias de las desigualdades económicas en Brasil entre 1992 y 2014. A pesar del aumento de la asociación entre los ingresos de los cónyuges, el impacto neto de los cambios en las contribuciones económicas de las mujeres casadas durante el período analizado fue ecualizador.

Palabras clave: desigualdades de ingresos; famílias; trabajo feminino; matrimonio; mercado laboral 